\title{
Intellectual disability sport and Paralympic classification
}

\author{
Anna van Dijk ${ }^{1}$, Klára Dad'ováa, ${ }^{2}$, Irena Martínková ${ }^{3}$
}

1 Faculty of Kinesiology and Rehabilitation Sciences, KU Leuven, Belgium

2 Department of Adapted Physical Education and Sports Medicine, Faculty of Physical Education and Sport, Charles University, Prague, Czech Republic

3 Department of Kinanthropology and Humanities, Faculty of Physical Education and Sport, Charles University, Prague, Czech Republic

* Corresponding author: dadova@ftvs.cuni.cz

\begin{abstract}
Sometimes it might seem that elite disability sport, especially as represented by the Paralympic Movement, is only for athletes with an amputation, or a spinal cord injury, or cerebral palsied or blind athletes, rather than for athletes with an intellectual disability (ID). However, after we set out the various opportunities open to ID athletes, that offer different kinds of sporting engagement, we find interesting and alarming issues with respect to the elite competitive event offer for athletes with ID. In this paper, we discuss the following: the problem of inclusion, some concerns that arise in the classification of paralympic athletes such as self-declaration and eligibility, the open nature of ID sports competition, and the sport offer available for these athletes.
\end{abstract}

\section{KEYWORDS}

intellectual disability; paralympic sport; classification; ethics

\section{DOI}

https://doi.org/10.14712/23366052.2017.2

(c) 2017 The Authors. This is an open-access article distributed under the terms of the Creative Commons Attribution License (http://creativecommons.org/licenses/by/4.0), which permits unrestricted use, distribution, and reproduction in any medium, provided the original author and source are credited. 


\section{INTRODUCTION}

At first sight it might seem as though the athletes represented in paralympic sport are those with certain relatively visible disabilities - those with an amputation, or a spinal cord injury, or cerebral palsied or blind athletes - rather than those with an intellectual disability (ID), who are, however, usually estimated to be $2-3 \%$ of the general population (Tilinger et al., 2012, p. 119). Firstly, we will examine what types of competitions there are for athletes with ID and what is their purpose, and secondly we will turn to the issues of Paralympic Games, since they pose many questions, especially because of the necessity to fairly determine the winner.

\section{Participation of athletes with ID in sport}

Presently, there are four main types of multi-sport international events on offer for athletes with ID: Paralympic Games, Special Olympics, Global Games and Trisome Games. There is no other disability group that has so many possibilities of multi-sport international events. So we should highlight the main principles espoused by these events and their organising bodies, including their mission statements, with a view to differentiating the very disparate kinds of participation they offer.

1. The Paralympic Games (PG), is organised by the International Paralympic Committee (IPC), which was founded in September 1989. Members of IPC are: International Sport Federations (IFs), National Paralympic Committees (NPCs), International Organisations of Sport for the Disabled (IOSDs) and Regional Organisations. IOSDs include organisations for blind athletes, athletes with cerebral palsy, amputee and wheelchair athletes, and also athletes with intellectual disability, who are governed by International Sports Federation for Persons with an Intellectual Disability (INAS). PG have been held every four years since 1960 (summer games), and 1976 (winter games). Athletes with intellectual disabilities officially participated in the Paralympics alongside other impairment groups for the first time in Atlanta, 1996.

The IPC Mission statement gives as its main aim:

Organise successful competitions as part of a stable calendar while encouraging participation and development at all levels and promoting the core values of the Paralympic Movement (IPC, 2013a, p. 6).

This aim was expressed by IPC CEO Xavier Gonzalez in his presentation of strategic plans for the various sports at the IPC General Assembly in 2013 in the following terms:

Our vision is to provide a platform for para-athletes to regularly practice and to showcase their ability to their full potential and to reach their sporting pinnacle and dreams (IPC, 2013b).

An updated IPC (2015b, p. 14) statement of aspiration, vision and values reads:

To make for a more inclusive society for people with an impairment through para-sport. 
The Paralympic Games are the world's number one sporting event for transforming society's attitudes towards impairment [...]

To enable para-athletes to achieve sporting excellence and inspire and excite the world.

The IPC values are given as: courage, determination, inspiration and equality (2015b, p. 14). So, it seems that the Paralympic Games are mainly about inclusion, promotion of participation and development of people with disabilities. However, the Paralympic Games are quite different from the Special Olympics, which also highlight inclusion.

2. The Special Olympics (SO) were founded by Eunice Kennedy Shriver in 1968, after six years of experimenting with informal events. The first International Special Olympics Summer Games were held in 1968 at Soldier Field in Chicago, when a thousand people with intellectual disabilities from USA and Canada competed in track and field, swimming and floor hockey (see Special Olympics, 2017). Since then, they have spread all over the world as a global movement. It is the only non-Olympic organisation authorized to use the name 'Olympics', having been officially endorsed and recognized by the International Olympic Committee (IOC) in 1988. (See more in Brittain, 2016, pp. 199-201.) The structure of international SO events is also four-year cycle since 1968 (summer games), and 1977 (winter games).

The mission of Special Olympics is to provide year-round sports training and athletic competition in a variety of Olympic-type sports for children and adults with intellectual disabilities. This gives them continuing opportunities to develop physical fitness, demonstrate courage, experience joy and participate in a sharing of gifts, skills and friendship with their families, other Special Olympics athletes and the community (Special Olympics, 2017).

The slogan of the SO also demonstrates a focus on the value of the competitive experience, rather than on winning or excellence: "Let me win. But if I cannot win, let me be brave in the attempt" (Lantz \& Marcellini, 2017). The aim of inclusion is illustrated by its adoption of a 'unified sports' model, adopting the principle of 'reverse integration', meaning able-bodied athletes participating in sport for people with disabilities.

3. The INAS Global Games (GG) have their origin in the IPC ban on athletes with ID from international paralympic competition after the Sydney 2000 PG. They were held for the first time in Bollnás, Sweden in 2004, and have been held four times since. The next GG, which are the largest international sporting event for athletes with ID, will be held in Brisbane, Australia, in 2019, also now following a 4-year cycle.

The IPC banned ID athletes from international competition after the Sydney 2000 PG because of a cheating scandal. The Spanish ID basketball team had included athletes with no ID, and so athletes with ID were excluded from the Paralympic Games for the following 12 years (Brittain, 2016, pp. $204 \mathrm{ff}$.; Kwon \& Block, 2012; Tomlinson, 2013). This initiated the Global Games movement, governed by INAS, the International Sports Federation for Persons with Intellectual Disability within the Paralympic Movement, who manage the eligibility process for ID sport competition and promote inclusion through sport. Their vision is as follows: 
We are inspired by a belief that an intellectual disability should not be a barrier to enjoying and being the best in sport. INAS' vision is that athletes with an intellectual disability across the World have the opportunity to achieve excellence in sport and high-level competition (INAS, 2010).

4. The Trisome Games (TG) are a new concept of competition for athletes with Down syndrome. The first TG were hosted in Florence, Italy, in the summer of 2016. They are organised by a new international multi-sport federation: the Sport Union for athletes with Down Syndrome (SUDS). They are based on the idea that people with Down syndrome have a specific disadvantage - both physiological and intellectual (Lantz \& Marcellini, 2017), and sometimes even physical (orthopaedic) - and these multiple disabilities make it more difficult for them to compete with those who only have intellectual disabilities. SUDS' aim is also to advocate a specific 'trisomy 21' category in the Paralympic Games.

Now, whilst we can see that all the above-mentioned organizations exist in order to enable and promote sport participation for athletes with ID, they do so with different priorities and values, and with different strategies and purposes. So, next, we need to highlight the differences between them.

The Paralympic Games focus on athletes with all kinds of disabilities and athletes with ID are just one among many disability groups. However, they share the same aspiration for all of these groups (with physical as well as intellectual disabilities). They give athletes with ID a chance to develop and excel in sports - professionalism and fair competition is important. The inclusion here is rather inclusion into the sporting community of athletes with disabilities who have reached elite performance levels and met qualifying standards (Brittain, 2016, p. 202), and who are striving towards "testing your body to its absolute limits" (IPC, 2015b, p. 14).

For this, a reliable classification system is of the highest importance, because it guarantees fairness. It is important to acknowledge that it is not easy to prepare a fair competition for athletes who differ so vastly from each other. And so the requirement of fair competition limits the chances and openness of participation, since athletes are required to submit to detailed scrutiny for fairness, which demands differentiation, which thus separates athletes into various groups rather than bringing them together. This also limits the number of athletes who can participate in these events.

Also, though winning is not ideologically central to the PG, it goes hand in hand with the focus of Paralympic Games (the values of fair competition, excellence, etc.):

Although winning is not central to Paralympism as formulated by the IPC, it is a major consideration for National Paralympic Committees when making team selection. National Paralympic Committees emphasize winning since they receive greater publicity and increased funding based upon their position in the medal table (Howe, 2008, p. 508).

On the other hand, the Special Olympics also highlight 'inclusion', by which they however mean including people of different ability levels, with and without special needs, doing sports and games together, and so connecting people within their communities. With this kind of setting, they are not so much concerned with fair and equal 
competition aiming for excellent performance; but rather with providing experience and enjoyment from active participation in sport, whilst giving all kinds of people with an interest in sport the opportunity to meet and share this interest (see more in Dowling et al., 2013). Although athletes are placed in divisions with others of similar ability (Brittain, 2016, p. 202), there is no great need for exact classification in this setting. Because of this, the Special Olympics can allow various kinds of sports and movement activities, without restricting them because of insufficient competition or classification problems (Howe, 2008, p. 510). In short: "This system is designed to challenge each athlete to do his or her best while providing a meaningful and enjoyable experience" (Brittain, 2016, p. 202).

The Global Games follow a similar pattern to the Paralympics, aiming at the excellence of athletes and highest possible level of competition. This is obvious, because they are organized by INAS, which is a member of IPC. Basically, they filled the gap in elite competition for athletes with ID during the period when these athletes were not allowed to enter the Paralympic Games. This project was successful in enabling the retention of competition at an elite level, with the possibility to 'do it in our own way' without IPC restrictions. However, we might say that their honesty reveals an admission that their goals include pursuing sport at the elite level of competition.

The brand new Trisome Games are based on the idea that people with Down syndrome need their own events because of multiple disability. Their aim is also to compete and win, but as they were open to any person with Down syndrome, without any special concern about the ability level of the athletes, they are more similar to the Special Olympics concept (Lantz \& Marcellini, 2017).

While interpreting the word 'inclusion' in different ways, and having different takes on inclusion options, it is important to highlight the value of these various events in giving athletes with ID different possibilities for training and competition (performance). However, various problems need to be discussed. Some of these topics have been discussed previously, but mainly with regard to athletes with physical disabilities, rather than intellectual disabilities (e.g. Bredahl, 2011; Harris, 2010; Tweedy \& Vanlandewijck, 2011). Nevertheless, the group of athletes with intellectual disabilities is very specific and needs special attention.

\section{Classification of athletes with ID}

One of the key differences of a disability sport compared to an able-bodied sport is classification. It is a requirement of Paralympic sport that the athlete self-identify as disabled, and submit to disability classification. Its goal is to enable as fair a competition as possible by eliminating the impact of type and level of disability on the chance to win. Thus, proper categorization is of immense importance for athletes with disability so that the sport competition can be fair. However, there are many challenges in classifying the athletes properly, including athletes with ID (see Howe, 2008, p. 510). The classification system of the Paralympic Games is very complicated for the uninitiated, and there are many rules that determine the eligibility of an athlete in a certain sport, so we will now briefly set out the current classification system.

The IPC uses a three-step system, which asks the following questions:

1. Does the athlete have an eligible impairment for this sport? 
2. Does the athlete's eligible impairment meet the minimum disability criteria of the sport?

3. Which sport class describes the athlete's activity limitation most accurately? (IPC, 2017)

Before we look at the issues of eligibility, self-declaration and eligibility by proxy, sport class and sports offer, we would like to summarize the fundamentals of classification.

At the beginning of paralympic sport, classification was focused on the kind and level of the disability based on a clinical diagnosis (i.e. medical classification). Later on, a functional classification system was adopted, firstly by Cerebral Palsy - International Sports and Recreation Association (CP-ISRA). This put emphasis on function in relation to a particular sport, which enabled the integration of athletes from different disability groups into one sport class (Vanlandewijck \& Chappel, 1996). Currently, Tweedy and Vanlandewijck (2011) describe two types of classification that are used in general sport: performance and selective classification.

A performance classification system is based on the performance level of the athlete. If the athlete performs on a higher level he or she will move on to a higher class in order to compete against other athletes with the skills, just like the belt system in Karate (Tweedy \& Vanlandewijck, 2011, p. 261). In sport for athletes with intellectual disability, performance classification is used in Special Olympics events.

A selective classification system, however, is based on pre-determined characteristics of the athlete, such as weight, gender, age, etc. This system is used, for example, in boxing and judo, where weight determines in which class the athlete will compete (Tweedy \& Vanlandewijck, 2011, p. 261). The IPC has chosen to classify athletes based on selective classification: "The IPC is committed to the development of selective classification systems, not performance systems” (ibid., p. 262). It has done this in order to prevent the movement of an athlete with improved abilities (e.g. through training) to a class with a higher number, which would give a lower probability of winning.

As the validity of classification was still in question, it was proposed to develop evidence-based systems, including full eligibility criteria and assessment methods. Guidelines for classification are described in the Classification Code, first approved in 2007 (after several years of proposals and comments), and updated on the IPC website in 2015 (IPC, 2015b). Nowadays, it also involves international standards for: eligible impairments, athlete evaluation, protests and appeals, classifier personnel and training, classification data protection, classification model rules and models of best practice.

\section{Eligibility of athletes with ID}

Eligibility is based on the kind and degree of disability of the athlete. The IPC describes ten eligible impairment types. As well as impaired muscle power, impaired passive range of movement, limb deficiency, leg length difference, short stature, hypertonia, ataxia, athetosis and visual impairments, we find also intellectual impairment.

Eligibility is strongly connected with a minimal disability for the particular sport. As Vanlandewijck and Chapel (1996) point out, it is the borderline of disqualification of an athlete. If an athlete is disqualified, he or she has to compete with able-bodied 
athletes. Eligibility and minimal disability might differ from sport to sport. For each sport different eligibility criteria are set up based on the degree of disability, in order to create as fair a competition as possible. This is a controversial topic because there are different perceptions of what counts as more or less of an impairment in particular sports.

For example, minimal disability in wheelchair basketball (a player with 4.5 points) equals either no restriction in trunk rotation or leaning forward or sideways in spinal cord injury athlete, a foot amputation, or a $6 \mathrm{~cm}$ leg length difference). On the other hand, in swimming, the criteria are, for example,

- for physical impairment: loss of one hand or a movement restriction in one hip joint;

- for visual impairment: visual acuity and/or visual field of B3 class; and

- for ID swimmers, in addition to the sport-relevant impairment:

difficulties with regards to pattern recognition, sequencing, and memory, or having a slower reaction time,

or showing a higher number of strokes relative to their speed than able-bodied elite swimmers (IPC, 2015a, pp. 30-32).

What is crucial for eligibility is objective proof that the athlete is really 'disabled' enough to be allowed to compete in a certain paralympic event. However, while proving that a part of the body is missing is relatively clear and easy, the assessment of an intellectual disability might be highly problematic, not only due to the inherent difficulty of making scientific and observational assessments, but also due to the understandable tendency of an athlete to accentuate his or her disability in order to achieve a certain classification, and thus to maximise the chances of victory (for athletes with intellectual disability, this is just a simple matter of being classified as an athlete with or without a disability, since the category is not sub-divided).

Classification cheating is a general problem in elite disability sport. For example, Etchells (2015) reports that the IPC believes that intentional misrepresentation of disability during the classification evaluation process of athletes "is in grave danger of undermining the credibility" of para-swimming and "overshadowing the performances" of the athletes. In the paralympic (and ID) context, grave damage was done in the well-known case of the gold medalist Spanish basketball team in Sydney 2000, which contained 10 members who had no ID at all ${ }^{1}$.

As a result, ID athletes were excluded from the Paralympics for 12 years, until new and more robust criteria and tests had been developed. At the Paralympic Games of 2012 in London, sports for athletes with an intellectual disability were reintroduced after evidence-based classification procedures had been developed. This can be described in three following steps (IPC, 2009; Lieberman, 2012, p. 40):

\section{Step one:}

If an athlete wants to enter paralympic sport in the ID class he or she needs to submit an 'Eligibility Application' to INAS. This application should prove the diagnosis of intellectual impairment (i.e. IQ measures 75 or below, limitations in adapted behaviour and age onset $<18$ years as defined by INAS (2016)). Then the INAS International

1 The details, circumstances and outcomes are fully documented in Brittain (2016, pp. 204 f.). 
Eligibility Committee conducts the verification process. Athletes who successfully pass step 1 are included in the 'Classification Master List' which is regularly updated by INAS. If the athlete is found eligible, the process will enter the next step.

\section{Step two:}

An on-site test will take place, which will focus on the assessment of cognitive domain factors that are relevant to the particular sport (possibly including assessment of reasoning, reaction time, visual-spatial abilities and working memory) in order to assess the 'sports intelligence of the athlete'.

The test score will be evaluated against sport-specific minimal disability scores and the athlete will be allocated the sport class that applies to ID athletes in a particular sport. [...] The sport-specific minimal disability scores may be revisited at regular intervals to strengthen the fairness of the system (IPC, 2009, p. 4).

\section{Step three:}

During competition an assessment of performance (overall sport proficiency, physical profile, technical and tactical skills, and environmental characteristics) may complete the athlete's assessment. Inconsistencies between the on-site testing and performance observation during competition can lead to protest against the allocation of the athlete to a certain sport class.

These steps fit well with the common algorithm of classification in athletes with physical disabilities, based on Strohkendl's (1985) earlier classification in wheelchair basketball - medical, functional and observational criteria. However, there are already problems with these new procedures. Firstly, IQ is used as the measure of ID, but recent studies have suggested that the use of a certain IQ level is fairly arbitrary (see Burns, 2015; Van Biesen et al., 2016). Secondly, some have suggested that, in any case, IQ is not related to sport specific intelligence:

When it comes to table tennis, says Van de Vliet, some on the autistic spectrum have no disability whatsoever. 'They are equally good, I would say, as any Chinese player who is at the Olympics' (Van Gilder Cooke, 2012). ${ }^{2}$

Even though there are studies showing that ID athletes have lower performance than able-bodied athletes in track-and-field ${ }^{3}$ (see Tilinger, 2013), this is not necessarily the case for other sports. Thirdly, the criterion of IQ presupposes that IQ is stable and does not change with age. But this is not so straightforward - studies do not agree on whether it changes, increases or decreases with respect to the assessment of low intellectual ability (e.g. see literature reviews by Begovac et al., 2009; Whitaker, 2008).

The IQ criterion may lead us to challenge the definition of 'intellectual impairment'. It is defined by IPC (2015a, p. 3) in the following way:

See also Burns (2015) with regard to table tennis.

Given the number of able-bodied athletes engaging in track-and-field in relation to athletes with ID in the same disciplines, it is no surprise that their performance is lower. 
Intellectual Impairment: A limitation in intellectual functioning and adaptive behavior as expressed in conceptual, social and practical adaptive skills, which originates before the age of 18 .

It is especially the element of "adaptive behavior as expressed in conceptual, social and practical adaptive skills" that is not necessarily adequately manifested with the IQ measures. Also, Van Biesen et al. (2016) claim that "[n]o significant correlations were found between any of the subtests and IQ score or between any of the subtests and training history".

So the question arises: what reasons does INAS have to hold on to IQ? If it is indeed not a significant measure for sport-related performance, why should it be retained as a measure? The question also arises: if 'sport specific intelligence' is proposed as a useful concept, won't it require us to start looking for a 'sporting IQ test'?

\section{The problem of improvement due to training}

It is important that a sport finds a classification system that identifies disability criteria that capture the particular kind of disability, in order to fit the selective classification system. If the criteria do not capture stable characteristics then, in fact, we are rather talking about a performance classification system, in which improvement may arise through learning and training. For example, due to training ID athletes might overcome certain gaps in their sports performance, and due to this they might out-train themselves out of their class - which for athletes with ID means disqualification of the athlete from paralympic sports (since there is only one class). So, although an athlete might have been found eligible at the onset of their career, due to an intensification of their training and a consequent improvement in performance, they might play better than before, which could bring their eligibility into jeopardy. That is why the IPC says:

The IPC is committed to the development of selective classification systems so that athletes who enhance their competitive performance through effective training will not be moved to a class with athletes who have less activity limitation - as they would in a performance classification system - but will be rewarded by becoming more competitive within the class they were allocated (Tweedy \& Vanlandewijck, 2011, p. 265).

The question is: can this principle be maintained in the case of ID athletes?

\section{Self-Declaration and eligibility by proxy}

Self-determination is an essential prerequisite for the development of the identity of the person with disability and his or her specific quality of life (Strohkendl, 1985). In paralympic classification, a qualifying requirement is that each athlete must self-identify as 'disabled' and must undergo a 'disability evaluation' in order to determine competition category. The athlete is required to self-identify according to self-specified and self-declared disabilities, verified by strict classification procedures, for competition in a particular event. But then we may ask: to what extent is an individual with an intellectual disability competent to declare himself/herself as intellectually disabled?

These athletes have to declare themselves as athletes with ID, and to specify their disability to the governing body INAS in order to participate. To be able to accomplish 
this, an athlete must be self-determining, which requires a certain level of intelligence, or competence. According to Nota et al. (2007) IQ level correlates with level of self-determination - the higher the intellectual level and social abilities of an individual, the higher the self-determination level. This means that athletes with a higher intellectual level and less impaired social abilities are more self-determining, and might therefore be in a position to declare themselves as ID in order to be found eligible by INAS. However, athletes with more severe intellectual disabilities might not be able to do this. According to Wehmeyer (2005), individuals with severe intellectual disabilities are less self-determinant and have less control over their lives. This raises the question whether (and if so, when) a parent or legal guardian might be empowered to declare ID on behalf of an ID athlete, to secure eligibility by proxy.

According to the United Nations Convention on the Rights of Persons with Disabilities (UN CRPD), article 12:

1. States Parties reaffirm that persons with disabilities have the right to recognition everywhere as persons before the law.

2. States Parties shall recognize that persons with disabilities enjoy legal capacity on an equal basis with others in all aspects of life (United Nations, 2006).

This suggests that the person with an ID has the legal right to determine whether or not they wish to declare themselves as ID. However, the situation is more complicated than that, since not all nations are signatories to the UN CRPD, and they may make local laws concerning the legal capacity of individuals. This may or may not include provision for a legal guardian to be appointed for an individual who is less self-determining.

This seems to give a reason why the IPC, in respecting the provisions of the UN CRPD, should accept the possibility of eligibility by proxy. To deny this possibility would be one way of excluding those with higher levels of disability - in effect, to install the criterion 'must have the ability to self-declare' as a criterion of exclusion within the ID category. This matter will be discussed further in the next section.

Finally, we should mention the general problem of athletes who might be reluctant to self-declare as persons with ID, because of the stigma attached to such a classification. For example, a Czech swimmer withdrew from paralympic swimming for just this reason (Franzlová et al., 2000, p. 65).

\section{Sport class}

As we said above, there are two types of classification that are used in sport: performance and selective classification; and the IPC has chosen to classify athletes based on selective classification. However, when we examine the criteria for eligibility in ID classification we might question to what extent it is selective. There is just one class for all ID athletes, and so this obviously cannot differentiate between various degrees of ID. This is selective insofar as only athletes who have met the ID eligibility criteria can participate in this class. But, amongst all those eligible, there will inevitably remain potentially huge differences in ID, and athletes might have to compete against others with a much lower or higher level of disability. 
As expected, the top eight athletes scored systematically higher on all variables of technical proficiency than the rest of the players with ID, yet their IQ scores were not significantly different (Van Biesen et al., 2012, p. 1526).

A consequence of this is that, since there is no classification within the category of ID, the group rules discriminate against the most disabled, since they will be systematically disadvantaged (see also discussion on this issue in Bredahl, 2011, p. 140). This suggests that the most disabled will gradually be excluded from the possibility of paralympic selection, and this contradicts the IPC's stated aim: “To enable para-athletes to achieve sporting excellence and inspire and excite the world" (IPC, 2015b, p. 14). This is also in contrast to the claim of Vanlandewijck and Chapel (1996) that classification groups should take into account varying degree of disability and to prevent drop-out of people with most severe disabilities.

We must ask why no attempt has been made to classify within the category of ID, in order to specify the degree of impairment. One explanation might be the lack of adequate scientific knowledge, or the difficulty in specifying appropriate criteria. Another explanation might refer to the capped number of athletes at the PG. If further classification is to be introduced, it would entail either the sharing of numbers between ID categories, or else a redistribution from other impairment groups. A third explanation might be more 'political', questioning the commitment of the IPC to include all individuals with intellectual disability. We might question whether this has anything to do with the image of the Paralympic movement and various prejudices against people with ID. A further explanation, as mooted in the previous section, could be that IPC/ INAS might be reasoning that the group should be identified with reference to the criterion of 'self-determination'. That is to say: only those athletes deemed capable of self-determination will be deemed eligible for IPC competition. If this is indeed the line of thought, it leaves us with two problems: firstly, what is the measure of self-determination? And secondly, can this measure assure us that this newly-defined ID group still needs no classification system within the group? - i.e. that equals will be facing equals in competition?

\section{The Sports Offer for ID athletes in the Paralympic Games}

The limitation of having just one class is not the only limitation, though. The engagement of ID athletes with paralympic sport is restricted by another problem: there are so few sports for them in which they can compete.

There are 23 summer paralympic sports (including para-dance-sport which is not at the Paralympic Games programme) and 6 winter paralympic sports. For each of those sports there are eligibility criteria, which means that athletes with certain disabilities may or may not be eligible to compete in certain sports. If we look at the summer sports, athletes with a physical disability have the widest choice (20 sports), followed by visually impaired athletes (only 3 sports - goalball, judo, football 5-a-side - but also selected classes in other sports, e.g. athletics, swimming, cycling, equestrian, triathlon). However, the current offer of paralympic sports for people with ID are:

- Athletics - long jump, shot put, 1500 m (sport class T/F 20)

- Swimming - $200 \mathrm{~m}$ freestyle, $100 \mathrm{~m}$ breaststroke, $100 \mathrm{~m}$ backstroke (sport class $\mathrm{S} 14$ )

- Table tennis (sport class T11) 
So, even though there are winter Paralymic Games, there are no winter sports for people with intellectual disabilities, who are therefore excluded. Also, when we focus on the selected summer sports, there has been no ID team sport in the Paralympic Games since basketball was corrupted by the Spanish team in the Sydney Paralympics.

The selected three sports, including altogether 7 disciplines, are all individual sports. It is true that they include three different relationships to an opponent - directly facing him/her (table tennis), competing alongside (swimming, running) and competing one after another, comparing performances (long jump and shot put), but since there is no team sport, athletes with ID miss the challenge of active cooperation with a team-mate (e.g. playing in doubles, or at least small team competitions). However, other international events for athletes with ID do offer team sports: basketball and football (INAS Global Games), basketball, soccer, handball, volleyball (Special Olympics), and football (Trisome Games).

We might ask: why are these not included in the Paralympics? Do these sports not enable the realization of the vision and mission of IPC? We might also ask: why are just these team sports on offer, and not others? What sports are suitable for people with ID? These are issues that require critical examination. At the moment, it looks as though the choice of sports on offer is dependent on arbitrary factors, such as the willingness or capability of an individual sport federation to take the initiative - whether they have the time, money and other resources to seek proper classification procedures, which are necessary for inclusion amongst the paralympic sports.

\section{CONCLUSION}

This paper has tried to identify and discuss some current issues in ID sport. We are well aware of the fact that is more difficult to create fair competition for these athletes because of nature of their impairment, which is not as visible and recognizable as with athletes with physical disabilities. However, if we do not put some effort into resolving some of the difficulties, there will remain many obstacles to the inclusion of those who aspire to be elite ID athletes.

\section{ACKNOWLEDGEMENTS}

This article was written within the institutional support of Charles University Progres Q19 and Q41.

\section{REFERENCES}

Begovac, I., Begovac, B., Majić, G., \& Vidović, V. (2009). Longitudinal studies of IQ stability in children with childhood autism - literature survey. Psychiatria Danubina, 21(3), 310-319.

Bredahl, A-M. (2011). Coaching Ethics and the Paralympic sports. In: A. R. Hardman \& C. Jones (Eds.), The Ethics of Sports Coaching (pp. 134-146). London: Routledge.

Brittain, I. (2016). The Paralympic Games Explained (2nd edition). London: Routledge.

Burns, J. (2015). The impact of intellectual disabilities on elite sports performance. International Review of Sport and Exercise Psychology, 8(1), 251-267. 
Dowling, S., Menke, S., McConkey, R., \& Hassan, D. (2013). Sport and Disability: The Special Olympics Youth Unified Sports Programme. In: D. Hassan and J. Lusted (Eds.), Managing Sport: Social and Cultural Perspectives (pp. 108-127). New York, NY: Routledge.

Etchells, D. (2015). IPC believes alleged intentional misrepresentation is in "grave danger of undermining the credibility” of Para-swimming. InsideTheGames website, 12 October 2015. Retrieved 23.03.2017 from: http://www.insidethegames.biz/articles/1030898/exclusive-ipc-believes-alleged-intentional-misrepresentation-is-in-grave-danger-of-undermining-the-credibility-of-para-swimming.

Franzlová, O., Groch, J., Hybš J., et al. (2000). XI. letní paralympiáda Sydney 2000 [XI. Summer Paralymics Sydney 2000]. Prague: Olympia.

Harris, R. (2010). Effects of the New Paralympic Rules for 2012 on the Fairness of the Competition. Updated 4/3/2017. Retrieved 23.03.2017 from: http://trainingandfitnessblog.com /index.php?q=london-2012-paralympics-new-rules.

Howe, P. D. (2008). The tail is wagging the dog: Body culture, classification and the Paralympic movement. Ethnography, 9(4), 499-517.

INAS (2010). Who we are. Our vision. Retrieved 23.03.2017 from: http://www.inas.org/aboutus/who-we-are-2/who-we-are.

INAS (2016). SECTION 4: POLICIES. 4.1 INAS ELIGIBILITY \& CLASSIFICATION: RULES, POLICY AND PROCEDURE. Updated 22/4/2016. Retrieved 23.03.2017 from: http:

//www.inas.org/wp-content/uploads/2010/11/4.1-Eligibility-Classification-Policy5.pdf.

International Paralympic Committee (IPC) (2009). Memorandum. P. Van de Vliet. Retrieved 23.03.2017 from: http://www.inas.org/wp-content/uploads/2010/11/2009_12_15-MemoIPC-Membership-ID-Athlete-Reinclusion_FINAL.pdf.

International Paralympic Committee (IPC) (2013a). Sports Strategic Plan, 2013-2016, Strategic Outlook for Paralympic sports managed by the IPC. Retrieved 23.03.2017 from: https: //www.paralympic.org/sites/default/files/document/131210143320016_WEB_IPC_13 _SP_General+131210.pdf.

International Paralympic Committee (IPC) (2013b). IPC publishes strategic plans for nine Paralympic sports. Retrieved 23.03.2017 from: https://www.paralympic.org/news /ipc-publishes-strategic-plans-nine-paralympic-sports.

International Paralympic Committee (IPC) (2015a). Explanatory guide classification summer. Retrieved 23.03.2017 from: https://www.paralympic.org/sites/default/files/document /150915170806821_2015_09_15\%2BExplanatory\%2Bguide\%2BClassification_summer \%2BFINAL\%2B_5.pdf.

International Paralympic Committee (IPC) (2015b). Strategic Plan 2015 to 2018. Retrieved 23.03.2017 from: https://www.paralympic.org/sites/default/files/document/150619133600866 _2015_06+IPC+Strategic+Plan+2015-2018_Digital.pdf.

International Paralympic Committee (IPC) (2017). Classification Introduction. Retrieved 23.03.2017 from: https://www.paralympic.org/classification.

Kwon, E., \& Block, M. E. (2012). Athletes with intellectual disabilities and the paralympics. Palaestra, 26(3), 25-27.

Lantz, E., \& Marcellini, A. (2017). Sports games for people with intellectual disabilities. Institutional analysis of an unusual international configuration. Sport in Society. Online first.

Lieberman, S. (2012). Classification at London 2012. The Paralympian, 2, 40-41.

Nota, L., Ferrari, L., Soresi, S., \& Wehmeyer, M. (2007). Self-determination, social abilities and the quality of life of people with intellectual disability. J. Intellect. Disabil. Res., 51(Pt 11), 850-865.

Special Olympics (2017). Special Olympics website. Retrieved 23.03.2017 from: http://www .specialolympics.org/Sections/What_We_Do/Our_Mission.aspx.

Strohkendl, H. (1985). Functional classification and self-determination of athletes in wheelchair sports. ISMGF Symposium. July 1985, Stoke Mandeville, Aylesbury. 
Tilinger, P. (2013). Comparison of Athletics Records of Intellectually Disabled Persons with Records of Intact Athletes. AUC Kinanthropologica, 49(2), 52-64.

Tilinger, P., Lejčarová, A., et al. (2012). Sport osob s intelektovým postižením [Sport of persons with intellectual disability]. Prague: Karolinum.

Tomlinson, S. (2013). Man that led shameful Spanish basketball team who pretended to be disabled to win Paralympic gold found guilty of fraud. Mail Online, 14 Oct 2013. Retrieved 12.03.2017 from: http://www.dailymail.co.uk/sport/othersports/article-2459172/Spanish-basketball-team-pretended-disabled-win-Paralympic-gold-guilty-fraud.html\#ixzz4b$7 \mathrm{Nc} 6 \mathrm{tdW}$.

Tweedy, S. M., \& Vanlandewijck, Y. C. (2011). International Paralympic Committee position stand - background and scientific principles of classification in Paralympic sport.

Br. J. Sports Med., 45(4), 259-269.

United Nations (2006). Convention on the Rights of Persons with Disabilities of 2006, article 12. Retrieved 27.03.2017 from: https://www.un.org/development/desa/disabilities/convention-on-the-rights-of-persons-with-disabilities/article-12-equal-recognition -before-the-law.html.

Van Biesen, D., Mactavish, J., Kerremans, J., \& Vanlandewijck, Y. (2016). Cognitive Predictors of Performance in Well-Trained Table Tennis Players with Intellectual Disability. Research in Developmental Disabilities, 53, 377-390.

Van Biesen, D., Mactavish, J., Pattyn, N., \& Vanlandewijck, Y. (2012). Technical proficiency among table tennis players with and without intellectual disabilities. Human Movement Science, 31, 1517-1528.

Van Gilder Cooke, S. (2012). How the Paralympics Is Welcoming Back Intellectually Impaired Athletes 12 Years After Cheating Scandal. Time, 29 August 2012. Retrieved 23.03.2017 from: http://olympics.time.com/2012/08/29/how-the-paralympics-is-welcoming-back-intellectually-impaired-athletes-12-years-after-cheating-scandal.

Vanlandewijck, Y., \& Chapel, R. (1996). Integration and classification issues in competitive sports for athletes with disabilities. Sport Science Review, 5(1), 65-88.

Wehmeyer, M. L. (2005). Self-Determination and Individuals with Severe Disabilities: Re-examining Meanings and Misinterpretations. Research and Practice for Persons with Severe Disabilities, 30(3), 113-120.

Whitaker, S. (2008). The Stability of IQ in People with Low Intellectual Ability: An Analysis of the Literature. Intellectual and Developmental Disabilities, 46(2), 120-128. 